\title{
Pattern of Otorhinolaryngological Diseases at Rural Medical Camps in Far Western Region of Nepal.
}

\author{
Reeba Karki ${ }^{1}$, Kiran Rai ${ }^{1}$.
}

${ }^{1}$ Department of ENT-HNS, Shree Birendra Hospital.

\begin{abstract}
Introduction: Nepal army has been organizing free medical camp in various parts of Nepal since many years. The free medical camp is committed to improve global health care in rural parts of Nepal. This study was conducted to describe the demographic and ENT-HNS diseases among the patients attending medical camps in two rural parts of far western region of Nepal (Humla-Simikot and Muggu- Talcha). Methods: Retrospective studies of all the patients attending ENT-HNS clinic of Simikot and Talcha medical camp from October 12th to October 16th 2011 were evaluated. Each patient was assessed by consultant ENT-Head and Neck surgeon. Only adult age group patient were included in the study. The disease was divided into four group i.e otology (ear disease), rhinology (nose disease), head and neck (throat disease) and normal finding groups. Results: Total numbers of 213 patients were analyzed in Simikot and 167 patients in Talcha. Among them otology group were 80 patients (37.5\%), rhinology 57patients (26.7\%), head and neck 55patients (25.82\%) and 21 patients $(9.85 \%)$ had normal findings in Simikot. Similarly in Talcha the patients were 84(50.29\%) in otology, 22(13.17\%) in rhinology, 49(29.34\%) in head and neck and12 (7.1\%) with normal findings respectively. Conclusions: Chronic otitis media (CSOM) is the most common ENT problems in both the rural areas. One of the major causes of hearing loss is CSOM so improvement of socioeconomic status and health care facilities will also be helpful in reducing the prevalence of CSOM.
\end{abstract}

Keywords: Chronic otitis media,Otology, Rhinology

\section{INTRODUCTION}

Health is vital for overall development of a human and determines his/her ability to acquire knowledge and skill. ENT (Ear, Nose, and Throat) disorders may affect this ability adversely and are common cause of consultation to general practitioners ${ }^{12}$. The provision of medical facilities to rural areas is a major objective of development in Nepal but the health care system in rural areas of our country has been confronted with problems of inequity, scarcity of resources, inefficient and untrained human resources, gender insensitivity and structural mismanagement ${ }^{3}$. Poverty, lack of knowledge is the major cause of not attending the medical facilties. Thus, Nepalease army organized these free health camps so that the target populations get benefited.

Chronic suppurative otitis media (CSOM) is one of the most common ear diseases in many of the developing countries including Nepal ${ }^{4}$. It is the most common cause of persistent mild to moderate hearing impairment in children and young adults ${ }^{5}$. During the recent decades, the incidence of chronic suppurative otitis media has dramatically declined due to improvements in housing, hygiene and antimicrobial chemotherapy ${ }^{6}$. According to World Health Organization, 42 million people (age $>3$ years) have hearing loss. The data on otorhinolaryngology from various Nepalese populations are insufficient. A proper understanding of the magnitude of ENT diseases and the factors associated with their occurrence in the community is important to enable formulation of health care services aimed at early detection and treatment of morbidities. The Present study was undertaken to determine the prevalence of ENT disorders in rural population in far western region of Nepal.

\section{Correspondence:}

Maj. Dr. Reeba Karki

Department of ENT-HNS

Shree Birendra Hospital, Kathmandu, Nepal.

Email: karkireeba@gmail.com

Phone: +977-9841403909 


\section{METHODS}

This was a retrospective study. All the data were collected from the medical camp organized by Nepalese army in two rural parts of far western region of Nepal -Humla ( Simikot)for three days and Muggu( Talcha) for two days from October $12^{\text {th }}$ to October $16^{\text {th }} 2011$. All the patients who presented to these two camps within the total period of five days were thoroughly evaluated by the same ENTHNS surgeon. A diagnosis was made by careful history taking and clinical examination. Patient with pediatric age group were excluded from the study as those patients were evaluated by pediatrician. On the basis of clinical presentation and examination, provisional diagnosis was made. Details were recorded and data was analyzed statistically using frequency and percentage.

\section{RESULTS}

ENT diseases in our study population were found to be more common among male (59.62\%) in Simikot whereas in Talcha it was female who outnumbered (52.10\%). Majority of the patients belonged to age group 21-30 years (32.39\%) in Simikot and less than 20 years $(28.14 \%)$ in Talcha with mean age 25 years in both areas (Table 1 ).

Table 1. Demographic Data

\begin{tabular}{|lll|}
\hline Sex distribution & Simikot & Talcha \\
Male & $127(59.62 \%)$ & $80(47.90 \%)$ \\
female & $86(40.37 \%)$ & $87(52.10 \%)$ \\
Total & 213 & 167 \\
Age Distribution & & \\
(years) & Simikot & Talcha \\
$<20$ & & \\
$21-30$ & $59(27.70 \%)$ & $47(28.14 \%)$ \\
$31-40$ & $69(32.39 \%)$ & $40(23.95 \%)$ \\
$41-50$ & $40(18.78 \%)$ & $31(18.56 \%)$ \\
$51-60$ & $19(8.92 \%)$ & $21(12.57 \%)$ \\
$61-70$ & $15(7.04 \%)$ & $20(11.98 \%)$ \\
$71-80$ & $10(4.69 \%)$ & $5(2.99 \%)$ \\
$81-90$ & $1(0.47 \%)$ & $1(0.60 \%)$ \\
$>90$ & - & $2(1.20 \%)$ \\
\hline
\end{tabular}

Diseases of auditory system (37.55\%) were the most common group of ENT problems among the Simikot population as well as in Talcha (50.29\%) followed by nasal disorders (26.76\%) in Simikot but in Talcha it was head and neck disorder (29.34\%) (Table 2).

The overall prevalence of chronic suppurative otitis media in Simikot was 35\% $(\mathrm{n}=28 / 80)$ and in Talcha was
$45.23 \%(\mathrm{n}=38 / 84)$ making it the most common otological problem. Wax $(20 \%, \mathrm{n}=16 / 80)$ was the second most common ear morbid condition in Simikot and it was wax and presbyacusis $(16.66 \%, \mathrm{n}=14 / 84)$ each in Talcha.

\section{Table 2. Pathological distribution}

\begin{tabular}{|lll|}
\hline Pathology & Simikot & Talcha \\
\hline Otology & $80(37.55 \%)$ & $84(50.29 \%)$ \\
Rhinology & $57(26.76 \%)$ & $22(13.175)$ \\
Head and Neck & $55(25.82 \%)$ & $49((29.34 \%)$ \\
Normal findings & $21(9.85 \%)$ & $12(7.18 \%)$ \\
Total & 213 & 167 \\
\hline
\end{tabular}

Other disorders of the otological group included tinnitus, Eustachain tube dysfunction, congenital hearing loss, Otitis media with effusion, foreign body ear (Table 3 ).

Among problems associated with nose, Deviated nasal septum (DNS) (42.10\%, $\mathrm{n}=25 / 57)$ was most common complaint in Simikot whereas DNS and Epistaxis $(45.45 \%, \mathrm{n}-10 / 22)$ wereOutnumbered in Talcha(18.5\%) Other conditions of nose like tumours, sinusitis, Inferior turbinate hypertrophy ( ITH) ,atrophic rhinitis, chronic rhinosinusitis(CRS),AC Polyp was seen .

Gastro esophageal disease (GERD) was troubling $52.72 \%(n=29 / 55)$ of our Simikot population and 73.46 $\%(\mathrm{n}=36 / 49)$ in Talcha. Other morbid conditions included acute tonsillitis, multinodular goiter (MNG), allergic pharyngitis, acute laryngitis, cervical lymphadenopathy.

Besides, few patients had non relevant ear, nose and throat complains and on examination were clinically normal

\section{DISCUSSION}

The neglecting of rural healthcare system is largely due to lack of doctors in the rural sector. Major problems being faced by this rural health sector are inadequate primary health care, high inadequacy of funding and trained manpower. A study done by Kishve, Sanjay P diseases of auditory system $(57.3 \%)$ were the most common group of ENT problems among the Indian population with otitis media $(18.25 \%)$ being the commonest ear, nose throat disorders as similar to ours ${ }^{7}$. Otitis media is the most common morbid condition of the ear and a leading cause of hearing loss. The high prevalence of otitis media in our study corresponds to the results obtained elsewhere in similar study. Prakash Adhikari in a study conducted among 2000 children aged between 5 and 13 years in Nepal found wax followed by chronic suppurative otitis media and otitis media with effusion as the most common 


Table 3. Otology (Ear Disorders)
\begin{tabular}{|lllllllllll|}
\hline Camp & CSOM-AA & CSOM-TT & Tinnitus & Wax & Presbyacusis & ET dysf & OME & Cong.H.L & F/B EAC & Total \\
Simikot & $2(2.5 \%)$ & $26(32.5 \%)$ & $8(10 \%)$ & $16(20 \%)$ & $8(10 \%)$ & $12(15 \%)$ & $5(6.25 \%)$ & $2(2.5 \%)$ & $1(1.25 \%)$ & $80(37.55 \%)$ \\
Talcha & $6(7.14 \%)$ & $32(38.09 \%)$ & $6(7.14 \%)$ & $14(16.66 \%)$ & $14(16.66 \%)$ & $8(9.52 \%)$ & $3(3.57 \%)$ & $(1.1 \%)$ & 0 & $84(50.29 \%)$ \\
\hline
\end{tabular}

Table 4. Rhionolgy (NoseDisorders)

\begin{tabular}{|lllllllllll|}
\hline Camp & DNS & Epistaxis & Vestibulitis & $\begin{array}{l}\text { Ca nose \& } \\
\text { PNS }\end{array}$ & ITH & $\begin{array}{l}\text { Atrophic } \\
\text { rhinitis }\end{array}$ & CRS & $\begin{array}{l}\text { AC } \\
\text { polyp }\end{array}$ & Total \\
Simikot & $24(42.10 \%)$ & $16(28.07 \%)$ & $2(3.5 \%)$ & $1(1.75 \%)$ & $9(15.7 \% 0$ & $1(1.75 \%)$ & $2(3.5 \%)$ & $1(1.75 \%)$ & $57(26.76 \%)$ \\
Talcha & $10(45.45 \%)$ & $10(45.45 \%)$ & $1(4.54 \%)$ & $1(4.54 \%)$ & 0 & 0 & 0 & 0 & $22(13.17 \%)$ \\
\hline
\end{tabular}

Table 5. Head and Neck (ThroatDisorders)

\begin{tabular}{|lllllllll|}
\hline Camp & GERD & Ac.Tonsillitis & MNG & Allergic Pharyngitis & $\begin{array}{l}\text { Cervical-lymph } \\
\text { adenopathy }\end{array}$ & Ac.Laryngitis & Parotitis & Total \\
\hline Simikot & $29(52.72 \%)$ & $8(14.54 \%)$ & 0 & $9(16.36 \%)$ & $6(10.90 \%)$ & $2(3.63 \%)$ & $1(1.8 \%)$ & $55(25.8 \%)$ \\
Talcha & $36(73.46 \%)$ & $5(10.20 \%)$ & $3(6.12 \%)$ & $3(6.12 \%)$ & $1(2.04 \%)$ & $1(2.04 \%)$ & 0 & $49(29.34 \%)$ \\
\hline
\end{tabular}

ear diseases in rural population ${ }^{8}$. J Hatcher et al also found chronic suppurative otitis media, wax and hearing loss among major form of ear diseases ${ }^{9}$. Annie Jacob in a study from rural population of south India diagnosed otitis media in $17.6 \%$ of children. ${ }^{10}$ Otitis media as a result of infection has been more common among rural population as against urban population ${ }^{11}$. More than the family type, it is the overcrowding which acts as a risk factor for ENT problem. Epistaxis is a common disorder that is usually due to local irritation in Kiesselbach's plexus. The most common disorders underlying epistaxis are local inflammatory diseases, infections, and digital trauma ${ }^{12}$. Most often the bleed is self limiting, however they may be recurrent.Gastro oesophageal reflx disease were most common among throat disorder in both Simikot ( 52.72\%) and also in Talcha $(73.46 \%)$ areas in our study. Similar study done by Rokonuzzaman SM et al also concluded $87.73 \%$ individuals in rural population had GERD ${ }^{13}$.

The prevalence of the various morbidities could be much higher in the general population, as many do not come to get medical help due to various socioeconomic barriers and also we had very limited time period for the camps.

The present study may br thr only study done in the western region as no other similar studies were found.

\section{CONCLUSIONS}

This study suggests that otitis media, deviated nasal septum, epistaxis and gastro oesophageal diseases are the most common ENT problems. Since, it is mostly the general practitioners who manage these cases; it is important that they are well verse with their diagnosis and treatment.

\section{REFERENCES}

1. ISD Scotland. Scottish Health Statistics. Edinburgh: Information and statistics division, National Health Service in Scotland; 1998.

2. McCormick A, Fleming D, Charlton J. Morbidity statistics from general practice, 4thNational Study 1992-1993. London: Office of National Statistics, HMSO; 1995.

3. Shaikh BT, Rabbani F. The district health system. A challeng that remains. East Mediterr Health J. 2004;10:208-14.

4. Okeowo PA. Observations on the incidence of secretory Otitis media in Nigerian children. J Tropical Paediatrics. 1985;31:295-8.

5. Biswas AC, Joarder AH, Siddiquee BH. Prevalence of CSOM among rural school going children. Mymensingh Med J .2005; 14: 152-5.

6. Eero Vartiainen M.D. Changes in the clinical presentation of chronic otitis media from the 1970s to the1990s. J Laryngol and Otol. 1998;112:1034-7. 7. Kishve Sanjay P. Ear, Nose, Throat disorders in paediatric patients in rural hospital in India. Australasian Medical Journal. 2010;6:786.

8. Prakash Adhikari. Pattern of ear diseases in rural school children: Experiences offree health camps in Nepal. Int J Pediatr Otorhinolaryngol. 2009;73:1278-80.

9. Hatcher J, Smith A, Mackenzie I, et. al. A prevalence study of ear problems in school children in Kiambu district, Kenya. Int J Pediatr Otorhinolaryngol. 1995;33:197-205.

10. Annie J, Vedantam R, Anand J, Abraham J. Hearing impairment and otitis media in a rural primary school in South India. Int J Pediatr Otorhinolaryngol. 1997;39:133- 8.

11. Sophia A, Isaac R, Rebekah G, Brahmadathan K, Rupa V. Risk factors for otitis media among preschool, rural Indian children. Int J Pediatr Otorhinolaryngol. 2010;74:677-83.

12. Guarisco JL, Graham HD. Epistaxis in children: causes, diagnosis, and treatment. Ear Nose Throat J. 1989;68:522-30.

13. Rokonuzzaman SM, Bhuian MR. Epidemiologic study of gastro esophageal disease in rural population.Mymensingh Med J. 2011;20:46371. 